\title{
Inovasi Pengolahan Limbah Bunga Kopi Untuk Minuman Teh Sebagai Produk Sampingan Petani Kopi Di Wilayah Hutan Kemasyarakatan Sesaot
}

\author{
Bambang Supeno*, Meidiwarman, Tarmizi, M Taufik Fauzi, Hery Haryanto \\ Fakultas Pertanian Universitas Mataram, Jl. Majapahit 62 Mataram, NTB
}

Kata Kunci: Inovasi, limbah, bunga, kopi, teh

\begin{abstract}
Abstrak: Tanaman kopi merupakan tanaman unggulan daerah NTB kedua setelah Kakao dan menghasilkan banyak limbah dalam proses produksinya. Limbah tanaman kopi terdiri atas daun kopi hasil wiwilan, kulit buah kopi dan bunga kopi. Bunga kopi nampaknya masih belum banyak termanfaatkan, sehingga kegiatan ini dilakukan. Tujuan dari kegiatan ini adalah untuk memberikan inovasi pengolahan limbah bunga kopi menjadi minuman teh sebagai produk sampingan petani kopi di kawasan HKM Sesaot. Pelaksanaan kegiatan dilakukan di Desa Buwun Sejati, Kecamatan Narmada pada Bulan April hingga Agustus 2019. Metode yang dilakukan adalah kaji terap pada beberapa kelompok tani kopi di kawasan Hkm Sesaot. Hasil kegiatan ini nampak seperti berikut : (a) dihasilkan produk olahan limbah bunga kopi yang memiliki nilai ekonomis tinggi, yaitu teh bunga kopi, (b). Produk samping olahan limbah bunga kopi secara ekonomis sangat menguntungkan, sehingga secara langsung perlahan dan pasti pendapatan kelompok tani kopi meningkat. (c). Teh bunga kopi telah terkemas dengan berlabel merek dagang sesuai dengan kreasi kelompok masing-masing desa lokasi, layak untuk dijadikan produk unggulan daerah.
\end{abstract}

\section{Korespondensi: bsupeno59@unram.ac.id}

\section{PENDAHULUAN}

Indonesia saat ini merupakan negara penghasil kopi terbesar di Asia Tenggara dan terbesar ketiga di dunia setelah Brasil dan Vietnam. Ketiga negara tersebut mengekspor 47 persen dari seluruh volume ekspor kopi dunia dengan pangsa pasar masing-masing: Brasil 28 persen, Vietnam 12 persen dan Indonesia 7 persen. Nilai ekspor kopi dalam lima tahun terakhir meningkat sekitar 21,64 persen per tahun

Dengan kenyataan tersebut menjadikan Kopi sebagai salah satu komoditas andalan perkebunan penghasil devisa negara Indonesia. Tahun 2010 memberikan nilai devisanya sebesar 845,54 juta dolar AS dan pada tahun 2011 naik menjadi 1,06 miliar dolar AS selanjutnya kembali naik menjadi 1,25 miliar dolar AS pada 2012 dan pada tahun 2013 nilai tetap sama sekitar 1,25 miliar dolar AS. Nilai tersebut merupakan sumbangan dari produksi Nasional yang mencapai 638.647 ton pada tahun 2011 dan naik 2,8 persen pada tahun 2012 menjadi 657.138 ton selanjutnya naik kembali pada tahun 2013 sebesar $1,98 \%$ menjadi 670.000 ton.

Pemerintah Provinsi Nusa Tenggara Barat telah menetapkan komoditi perkebunan kopi dan kakao sebagai dua komoditi unggulan selain kelapa dan jambu mete. Rata-rata produksi biji kopi dan luas areal kopi NTB mulai dari tahun 2008 sampai 2013, yaitu total luas areal produksi sekitar 12.495,38167 hektar dan 5.105,025 ton total produksi dari potensi areal yang mencapai 46.451,65 Ha (Dinas Perkebunan Provinsi NTB, 2014). 
Tiga lokasi sentra pengembangan kopi spesialti NTB, yaitu Rinjani, Tepal dan Tambora, yang dikenal dengan Kopi RITERA (Rinjani, Tepal, Tambora). Kopi Spesialti NTB menduduki 30 besar nasional dari 144 peserta dengan nilai 84,42, naik 4,42 point dari pertengahan 2011 meraih angka 80, khususnya Kopi Sajang/Rinjani dan Kopi Tepal bersertifikat Organik dari Lembaga Sertifikasi Organik Seloliman (LeSOS) Mojokerto - Jawa Timur dan diakui oleh Peneliti yang berkualifikasi Q-grader dari Specialty Coffee Association of America (SCAA) yang diakui dunia.

Perkebunan kopi rakyat di pulau Lombok sebagian besar berada di kawasan hutan kemasyarakatan (Hkm). Salah satu kawasan $\mathrm{Hkm}$ adalah di daerah sesaot yang memiliki luas tanaman kopi rakyat seluas 185 ha. Kawasan Hkm Sesaot dikerjakan atau digarap sekitar 1.224 kepala keluarga (KK) yang dipisahkan menjadi 23 kelompok tani hutan (KTH) (Disbun 2017).

Dalam proses produksi kopi tersebut banyak menghasilkan limbah baik itu berupa kulit buah kopi paska panen maupun limbah daun-daun hasil rampasan atau wiwilan selama dalam proses produksi di lapangan. Salah satu limbah yang belum dilirik untuk dikembangkan menjadi produk bernilai ekonomis tinggi adalah mahkota bunga kopi. Potensi bunga kopi yang dihasilkan per pohon mencapai 19.342 kuntum/tanaman, sehingga dalam satu hektar kebun kopi dihasilkan sebanyak 30.947.200 kuntum (Supeno dan Erwan. 2018; Supeno dan Erwan 2017). Limbah bunga kopi tersebut belum banyak ditangani sehingga masih dibiarkan mengering diranting ranting dan tampak tidak ada manfaatnya. Kondisi tersebut sebenarnya yang masih dapat dimanfaatkan dan diolah sebagai produk sampingan kopi. Diketahui bunga kopi banyak mengandung antioksidan, vitamin dan mineral yang bagus untuk kesehatan.

Berdasarkan uraian tersebut di atas telah dilakukan kegiatan dengan judul "Inovasi Pengolahan Limbah Bunga Kopi Untuk Minuman Teh Sebagai Produk Sampingan Petani Kopi Di Wilayah Hutan Kemasyarakatan Sesaot."

\section{METODE KEGIATAN}

\section{A. Lokasi dan Waktu Kegiatan}

Lakasi kegiatan dilakukan Desa Buwun Sejati yang terletak di wilayah Kecamatan Narmada, kabupaten Lombok Barat. Kegiatan dilakukan mulai bulan Mei hingga Juli 2019.

\section{B. Pelaksanaan Kegiatan}

Kegiatan program ini dilkasanakan dengan metode pelatihan yang dilanjutkan dengan kerja praktek di lapang dan kaji tindak partisipatif aktif (partisipatory action research) di lapang secara aktif sejak persiapan hingga evaluasi. Kegiatan lapangan dilaksanakan oleh Oleh tim pelaksana Pengabdian Masyarakat yang didanai oleh Universitas Mataram. Pelaksanaan dilibatkan mahasiswa yang menyusun skripsi dibawah bimbingan Tim Pelaksana kegiatan sebagai Dosen Pembimbing 


\section{Kelompok Sasaran}

Sasaran dari program kegiatan ini adalah masyarakat yang ada di tiga Dusun lokasi yang memiliki profil seperti berikut: (1) pekerjaan sebagai petani kopi, (2) berdomisili di desa setempat, (3) memiliki kebun atau lahan garapan tanaman kopi di Hkm, (4) mempunyai kemauan dan semangat dalam pengolahan limbah kopi, (5) bersedia mematuhi dan mengikuti petunjuk bimbingan yang dicontohkan, (6) bersedia menyebarluaskan ilmu yang telah diterima kepada para petani lain yang menginginkannya, (7) bertanggung jawab terhadap bantuan dalam peningkatan usaha produksi kopi dan olahan limbahnya.

\section{Petani Peserta Kegiatan}

Hasil observasi dan sosialisasi yang telah dilakukan diperoleh 30 petani yang tergambung dalam kelompk tani hutan di kawasan Hkm Sesaot. Peserta kegiatan tersebar di setiap dusun Desa Buwun Sejati. Peserta didampingi untuk memproduksi teh bunga kopi hingga selesai kegiatan (pemasaran).

\section{E. Program Pengembangan Usaha Pembuatan Teh}

Pelaksanaan kegiatan dimulai dengan melakukan seleksi peserta, pelatihan dan kerja lapang yang dimulai dari pembuatan teh dengan beberapa tahapannya, yaitu, Cara memanen bunga kopi, sortasi, pengeringan, pengemasan dan pemasarannya, Design kemasan, pemasan dan evaluasi.

Proses pengolahan bunga kopi tentunya dimulai dari pemilihan bunga kopi yang siap panen, waktu panen, cara pemanenan (petik) dan proses pengeringan. Pemilihan bunga dan waktu akan mempengaruhi aromanya. Waktu panen tentunya harus diperhatikan agar tidak merusak bakal buah. Waktu panen sebaiknya dilakukan setelah bunga kopi melakukan penyerbukan (oleh serangga atau angin). Kondisi ini diharapkan agar aroma harum bunga kopi masih ada untuk mendapatkan kualitas yang baik. Keadaan ini diperkirakan sekitar 3-10 hari setelah mekar penuh tergantung jenis dan lokasi tanaman kopinya. Pemanenan ini tentunya harus ekstra hati-hati sehingga hanya mahkota bunganya saja yang terambil dan

Bunga hasil panen dilakukan sortasi dari kotoran yang mungkin terbawa saat panen, seperti daun sengon kering, daun mahkota bunga atau kotoran lainnya. Bunga kopi yang terpilih selanjutnya dilakukan pengeringan di bawah sinar matahari hingga kering sekitar 3-5 hari pada kondisi sinar matahari penuh, dengan warna coklat muda. Kriteria lain adalah bunga bila di pegang sangat mudah dihancurkan dengan menggunakan tangan. Bunga kopi tersebut selanjutnya dihaluskan dengan tangan atau tetap utuh dan dilakukan takaran. Takaran bunga kopi disesuaikan atau atas dasar uji coba pembuatan teh yang memberikan hasil warn coklat, umumnya sebanyak satu sendok teh penuh (2-3 g). Bunga kopi yang telah ditakar tersebut dimasukkan dalam kantong kemasan teh celup yang telah dipersiapkan dan selanjutnya di kemas dalam kotak kardus. Kotak kemasan didesign sesuai dengan kesepatkan kelompok tani yang selanjutnya siap untuk dipasarkan. 


\section{Analisis Ekonomi}

Evaluasi hasil prodiksi teh dan pakan ternak hasil inovasi dilakukan dengan menghitung BEP Produk dan Harga yang akan dilakukan dengan menggunakan rumus berikut:

Rumus Break Event Point (BEP) untuk single product (Riyanto 2001) adalah:

$$
\begin{aligned}
& \mathrm{BEP}(\text { unit } / \mathrm{x})=\frac{F C}{(\mathrm{~S}-\mathrm{VC})} \\
& \text { atau } \\
& \mathrm{BEP}(\text { rupiah })=\frac{F C}{\left(1-\left(\frac{V C}{S}\right)\right)}
\end{aligned}
$$

Keterangan :

$\mathrm{FC}=$ fixed cost (biaya tetap)

$\mathrm{VC}=$ variable cost (biaya variabel)

$\mathrm{S}=$ sales (penjualan).

\section{HASIL DAN PEMBAHASAN}

Limbah bunga kopi di lokasi kegiatan sangatlah berlimpah dan dapat dikreatifkan menjadi produk yang memiliki nilai ekonomis tinggi, seperti teh bunga kopi. Namun tidak semua limbah bunga kopi tersebut bisa dimanfaatkan sebagai bahan minuman untuk mendapatkan kualitas yang baik. Karakter bunga kopi yang boleh dipanen untuk bahan teh adalah umur 3-10 hari setelah mekar penuh seperti pada Gambar 1. Bunga kopi yang siap dipanen atau paling lama untuk bisa diolah menjadi teh adalah berwarna coklat

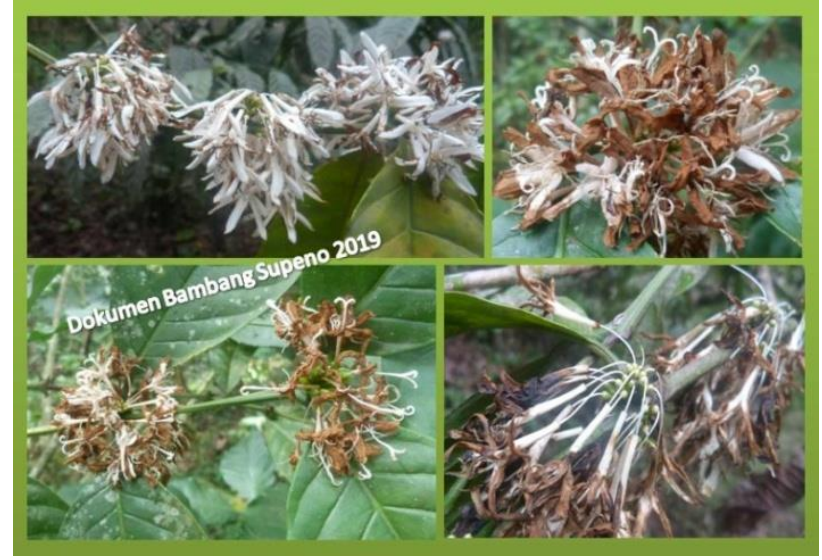

Gambar 1. Limbah bunga kopi yang bisa dimanfaatkan untuk minuman teh

Karakter bunga yang tidak bisa digunakan sebagai bahan pembuatan teh adalah warna bunga yang telah menghitam atau rusak akibat serangan jamur (Gambar 2) 


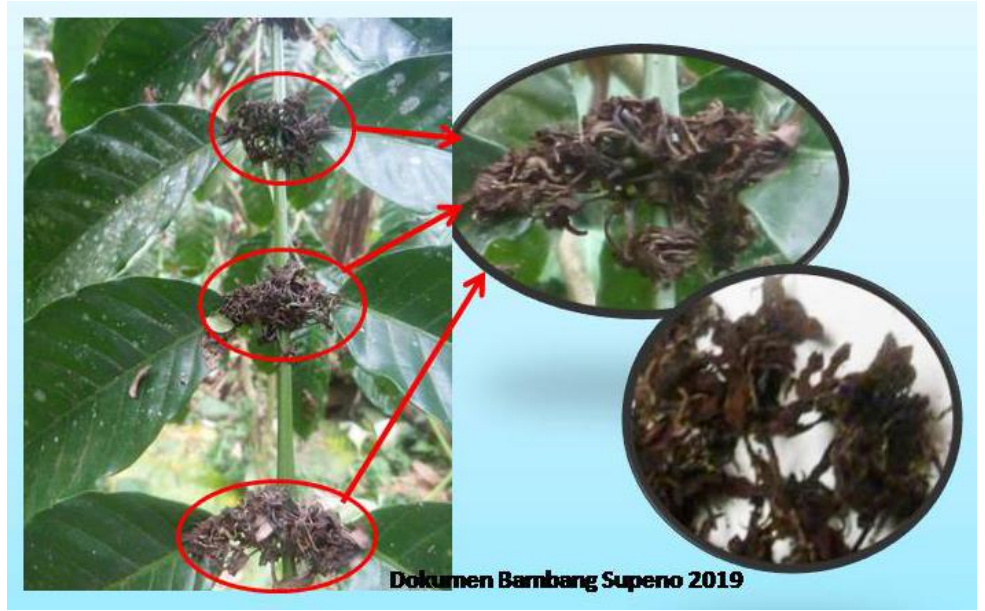

Gambar 2. Limbah bunga kopi hitam mongering di ranting

Produk teh bunga kopi (blossom tea) yang selama ini belum terpikirkan oleh para petani kopi dan bunga kopi dibiarkan begitu saja hingga kering menghitam di ranting (Gambar 2.). Inovasi dan kreativitas produk ini telah membuka pengetahuan para petani kopi, khususnya peserta yang terlibat dalam kegiatan ini. Bunga kopi yang selama ini terabaikan begitu saja, ternyata memiliki kasiat yang bagus untuk kesehatan dan untuk inovasi usaha baru di desa sehingga mendatangkan pendapatan tambahan. Hasil pelatihan dari kegiatan ini telah diproduksi teh bunga kopi celup yang telah terkemas dalam kotak sesuai dengan kreasi kelompok tani (Gambar 3).

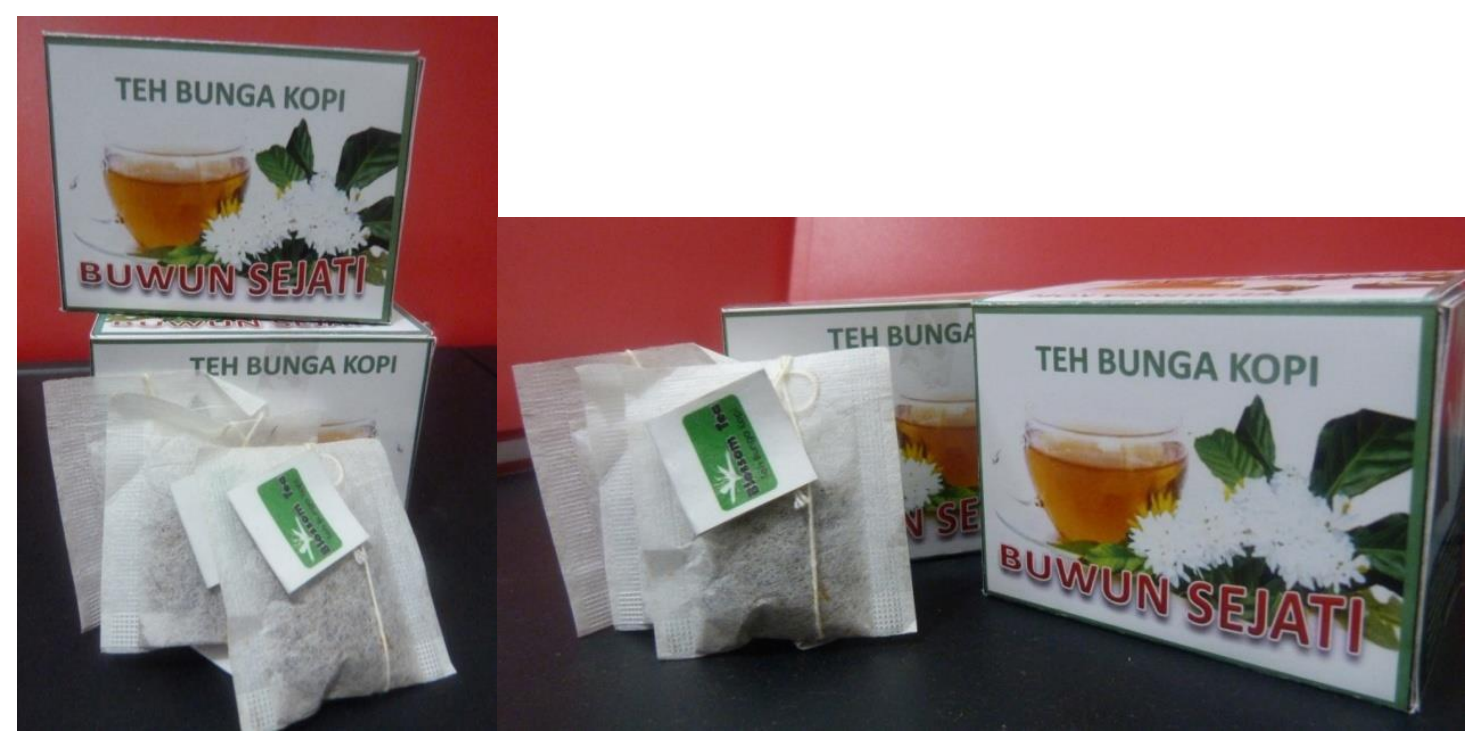

Gambar 3. Produk teh bunga kopi hasil pelatihan pengabdian dan siap dipasarkan

Hasil olahan limbah bunga kopi menjadi suatu produk samping yang dihasilkan oleh kelompok tani sangat memnungkinkan dikembangkan menjadi produk unggulan Desa. Produk tampak terkemas dengan bagus dan dicoba untuk dipasarkan sehingga dari uji coba tersebut dapat dihitung nilai ekonomisnya. Hasil analisis produk tersajikan dalam Tabel 1 berikut: 
Tabel 1. Hasil Analisis Ekonomi Produk Olahan Limbah Bunga Kopi di Desa Buwun Sejati.

\begin{tabular}{cc}
\hline Analisis & Hasil \\
\hline BEP Unit & 21 \\
BEP Rupiah (Rp) & 4.797 \\
B/C Ratio & 1,21 \\
\hline
\end{tabular}

Nilai ekonomis yang tersaji dalam Tabel 1. Menunjukkan bahwa produk minuman teh bunga kopi sangat memberikan nilai tambah bagi petani, yang sebelumnya tidak termanfaatkan sekarang bisa memberikan keuntungan. Secara rasional pelan dan pasti petani mendapatkan usaha baru. Titik impas dalam memproduksi teh ini adalah 21 untit kotak kemasan, artinya baru akan mendapatkan untung kalau diproduksi lebih dari 21 unit, dengan harga jual Rp 4.797. Keuntungan bisa direncanakan mau berapa persen untungnya tinggal mengalikan dengan harga jualnya. Sebagai contoh ingin untung $20 \%$ maka harga jual harus dinaikan 20\% ( Rp 4.797 + (20\%x Rp 4.797). Keuntungan yang diperoleh dari produksi teh celup bunga kopi (Gambar 3.) sekitar Rp 140.000,- per 50 kotak yang membutuhkan bahan baku sebanyak $0,5 \mathrm{~kg}$ bunga kopi.

\section{KESIMPULAN DAN SARAN}

Berdasarkan hasil kegiatan dan terbatas dalam ruang lingkup yang telah dilaksanakan dapat diberikan kesimpulan: (a) dihasilkan produk olahan limbah bunga kopi yang memiliki nilai ekonomis tinggi, yaitu teh bunga kopi, (b). Produk samping olahan limbah bunga kopi secara ekonomis sangat menguntungkan, sehingga secara langsung perlahan dan pasti pendapatan kelompok tani kopi meningkat. (c). Teh bunga kopi telah terkemas dengan berlabel merek dagang sesuai dengan kreasi kelompok masing-masing desa lokasi, layak untuk dijadikan produk unggulan daerah.

Hasil kegiatan ini disarankan untuk bisa dijadikan suatu produk unggulan Desa yang memiliki daya saing cukup baik untuk dikembangkan menjadi usaha kreatif masyarakat.

\section{Ucapan Terima Kasih}

Ucapan terimakasih penulis sampaikan kepada Yth. Dekan Fakultas Pertanian dan Ketua LPPM Unram yang telah membiayai, memfasilitasi kegiatan pengabdian kepada masyarakat dari sumber dana DIPA BLU Univeritas Mataram tahun anggaran 2019, dengan surat perjanjian nomor: 2166/UN18/LPPM/2019 Tanggal 02 Mei 2019. Kepala Desa Buwun Sejati dan kelompok Tani Hutan,Kepala Dusun lokasi kegiatan. Seluruh mahasiswa yang terlibat dan Tim pelaksana kegiatan disampaikan terimakasih atas kerjasamanya. Akhir kata semoga makalah ini dapat bermanfaat.

\section{DAFTAR PUSTAKA}

Awan. H., 2017. Laporan Akhir KKN-PPM di Desa Rempek. LPPM Universitas Mataram. $74 \mathrm{p}$. 
Darmawan. A., 2017. Laporan Akhir KKN-PPM di Desa Genggelang. LPPM Universitas Mataram. 84 p.

Direktorat Jenderal Perkebunan, 2015. Statistik Perkebunan Indonesia 2014-2016: KOPI. Direktorat Jenderal Perkebunan. Jakarta 97 p.

Ditjenbun (2006). Pedoman pemanfaatan limbah dari pembukaan lahan. Direktorat Jenderal Perkebunan. Departemen Pertanian.

Kabir. Z., 2017. Laporan Akhir KKN-PPM di Desa Sambik Bangkol. LPPM Universitas Mataram. 73 p.

Novita R., Andi Eviza, Sri Kembaryanti Putri, 2015. Proses Pembuatan Minuman Kawa Daun Di Sumatera Barat p 49-52 dalam Proseding seminar Nasional Ketahanan Pangan dan Pertanian Berkelanjutan : Peluang dan Tantangan Implementasi teknologi dalam Perspektif Nasional. Politeknik Pertanian Negeri Payakumbuh, Kabupaten 50 Kota Sumatera Barat

Prawirodigdo, S.; T. Herawati \& B. Utomo 2005. Pemanfaatan kulit kopi sebagai komponen pakan seimbang untuk penggemukan ternak domba. dalam I.W. Mathius; S. Bahri; Tarmudji;L.H. Prasetyo; E. Triwulanningsih; B. Tiesnamurti; I. Sendow \& Suhardono (eds.). Prosiding Seminar Nasional Teknologi Peternakan dan Veteriner. p. 438-444. Puslit-bangnak, Bogor.

Setiawan EA., Dimas Rahadian AM, Siswanti., 2015.Pengaruh Penyangraian Daun Kopi Robusta (Coffea Robusta) Terhadap Karakteristik Kimia Dan Sensory Minuman Penyegar. Jurnal Teknosains Pangan 4(2): 1-9.

Siringoringo FHT., Zulkifli Lubis, Rona J. Nainggolan. 2012. Studi Pembuatan Teh Daun Kopi. Jurnal.Rekayasa Pangan dan Pert., 1(1): 1-5

Supeno B dan Erwan. 2015. Karakteristik Bunga Kopi Dan Lebah Madu Dalam Mendukung Teknik Penerapan Sistem Terintegrasi Beternak Lebah Madu Dan Kopi Menuju Terciptanya 2 In 1 Penghasilan Petani Hkm. Makalah Seminar Insentif Riset SINas, Kementerian Riset danTeknologi“Membangun Sinergi Riset Nasional untuk Kemandirian Teknologi” Bandung 3-4 Desember 2015. 7 p.

Supeno B dan Erwan. 2015a.Teknik Penerapan Sistem Terintegrasi Beternak Lebah Madu Dan Kebun Kopi Dalam Mendukung Terciptanya Two In One (2-In-1) Penghasilan Petani Hkm. Laporan hasil penelitian Insentif Riset Terapan (RT). Lembaga Penelitian Universitas Mataram. 30 p.

Supeno. B., Laksmi E.N.M., dan Erwan, 2017. Teknologi Pemanfaatan Limbah Tanaman Kopi Secara Terintegrasi Dalam Meningkatkan Pendapatan Petani. Laporan Akhir Hibah-KKN-PPM. Universitas Mataram. 67 p. 